\title{
Tandem genes encoding $\sigma$-factors for consecutive steps of development in Bacillus subtilis
}

\author{
Céline Karmazyn-Campelli, Céline Bonamy, Bruno Savelli, and Patrick Stragier \\ Institut de Microbiologie, Bât. 409, Université Paris-Sud, 91405 Orsay Cedex, France
}

\begin{abstract}
During sporulation, Bacillus subtilis undergoes successive morphological changes that can be arrested at various stages by mutations in many genes. One of these, spoIIGB, encodes a transcriptional factor, $\sigma^{\mathbb{E}}$, which is necessary to proceed beyond stage II and to differentiate the cell in two compartments, the forespore and the mother cell. Mutations were introduced in an open reading frame located immediately downstream of spoIIGB. They block sporulation at stage III and define a new gene, spoIIIG, encoding a 260-amino-acid polypeptide highly similar to bacterial $\sigma$-factors. A promoter was identified in the spoIIGB-spoIIIG interval by transcriptional fusion to lacZ. It is turned on $1 \mathrm{hr}$ after the start of $\sigma^{\mathrm{E}}$ synthesis and is specifically activated in the forespore. The tandemly arranged spoIIGB and spoIIIG genes appear to encode homologous proteins that modulate transcription in a sequential fashion during sporulation.
\end{abstract}

[Key Words: $\sigma$-Factor; transcription; compartmentalization; sporulation; development; Bacillus subtilis]

Received October 7, 1988; revised version accepted December 15, 1988.

Genetic organization in higher organisms sometimes reflects the temporal or spatial role of related gene products during development. For instance, in most mammals, the $\alpha$-globin and $\beta$-globin genes are arranged in order of their sequential expression during development (Maniatis et al. 1980). In the Bithorax Complex of Drosophila, mutations are clustered in a series of phenotypic classes and aligned on the chromosome in the exact order of the body segments that they affect (for review, see Duncan 1987). Nothing equivalent has been described in Bacillus subtilis, a bacterium that elaborates a multiresistant endospore, according to a temporal and spatial sequence of gene activation, in response to nutrient depletion (for review, see Losick et al. 1986). Sporulation proceeds through several morphological stages $(\mathrm{O}, \mathrm{II}, \mathrm{III}, \ldots ., \mathrm{VII})$, each one involving the products of 5-10 different operons. These spo genes are scattered all around the chromosome without any noticeable organization.

Early steps of sporulation are dependent on the synthesis and activation of new $\sigma$-factors that modify RNA polymerase transcription specificity, namely the spoOH, spoIIAC, and spoIIGB gene products (see Losick et al. 1986). The latter, $\sigma^{\mathrm{E}}$ (formerly $\sigma^{29}$ ), plays a key role in the temporal program of transcription. Its synthesis in active form appears to be coupled to the formation of the asymmetric septum characteristic of stage II (Stragier et al. 1988) and is needed to allow the subsequent morphological modifications that lead to a compartmentalized system at stage III. Thereafter, differential gene expression occurs in the two subcellular compartments, the forespore and the mother cell. For instance, the $s s p$ genes, encoding small acid-soluble proteins accumulated in the spore, are turned on only in the forespore (Mason et al. 1988); conversely, the cot genes encoding the spore coat proteins are expressed only in the mother cell (cited by Panzer et al. 1989). Although the existence of additional $\sigma$-factors has been conjectured (Kunkel et al. 1988; Mason et al. 1988), the molecular mechanisms that control compartmentalized gene expression are still elusive.

In this paper we report the existence of a new gene, spoIIIG, tandemly arranged with spoIIGB, which potentially encodes a late $\boldsymbol{\sigma}$-factor. In the accompanying paper, Sun et al. (1989) demonstrate that the spoIIIG product is actually a $\sigma$ factor and that it is involved in forespore-specific gene expression.

\section{Results}

spoIIIG, a new stage III locus

The spoIIG locus (Fig. 1) was initially cloned as a $3.7-\mathrm{kb}$ $B a m H I$ fragment, and the sequence of the region covering the spoIIG41 and spoIIG55 mutations revealed the existence of an open reading frame encoding a $\sigma$-like polypeptide (Stragier et al. 1984). This polypeptide was identified as the inactive precursor of $\sigma^{\mathrm{E}}$ (Trempy et al. 1985; LaBell et al. 1987). Further characterization of the spoIIG locus indicated that it actually comprised two genes (Kenney and Moran 1987) and that the product of the first gene of the operon, spoIIGA, was likely to be the pro- $\sigma^{\mathrm{E}}$ processing enzyme (Stragier et al. 1988). The 


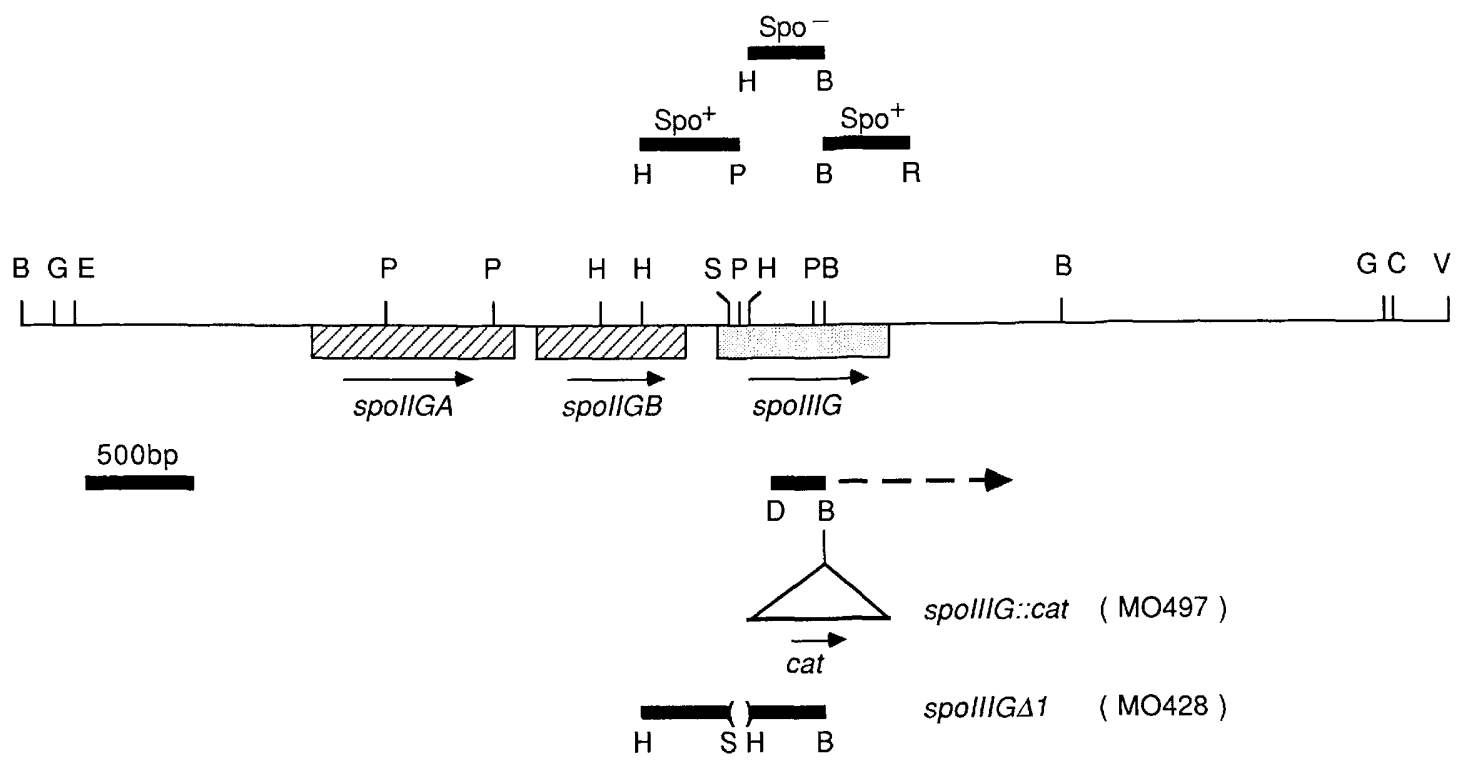

Figure 1. Characterization of the spoIIIG locus. (Top) The DNA fragments that were cloned in the integrative vector pJH101 and the associated Spo phenotype after transformation of strain 168 or JH642. (Middle) The hatched and dotted boxes indicate the open reading frames as determined by DNA sequencing. (Bottom) The interrupted arrow starts from the fragment that was used to walk up to the ClaI and EcoRV sites (see text). The site of insertion of a chloramphenicol resistance cartridge (not on scale) that inactivates the spoIIIG gene is indicated. The DNA fragments that were used to create the spoIIIGAl mutation are shown; they bracket a 70-bp region that was replaced by 40 bp provided by pUC and Bluescript vectors. The restrictions sites are abbreviated as follows: $B a m H I$ (B);

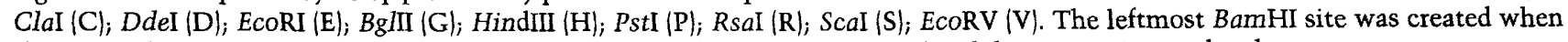
the spoIIG locus was cloned after partial Sau3A digestion (Stragier et al. 1984) and does not exist on the chromosome.

presence of that other gene immediately upstream of the pro- $\sigma^{\mathrm{E}}$-coding sequence (henceforth called spoIIGB) had first been pointed out by Kobayashi and Anaguchi (1985). They also indicated that a third open reading frame started 139 bp downstream of spoIIGB. We wondered whether that gene was also involved in sporulation.

From the data published by Kobayashi and Anaguchi (1985) it could be predicted that the rightmost HindIIIBamHI fragment carried by our original insert (see Fig. 1) was entirely within that third open reading frame. This DNA fragment was subcloned into a nonreplicative plasmid carrying an antibiotic resistance marker selectable in $B$. subtilis. Transformation of a wild-type $B$. subtilis strain with this recombinant plasmid led to disruption of the gene located downstream of spoIIGB by homologous recombination. The transformed clones remained unpigmented on nutrient agar plates, a phenotype associated with asporogeny. Electron microscopic examination of these clones grown in liquid sporulation medium confirmed this diagnosis and indicated that the cells displayed a classic stage III phenotype, the development being arrested after engulfment of the forespore by the mother cell (Fig. 2). Thus, the spoIIGB gene is followed by a spo gene, unidentified as yet, that we designate as spoIIIG, the next available name (Losick et al. 1986).

Two other mutations were introduced by marker replacement in the spoIIIG gene when its sequence became available (see Fig. 1 and Experimental procedures). The first one, spoIIIGA1, was intended to be an in-frame deletion between codons 18 and 42 . However, nucleotide sequencing revealed that an extra 18-bp HaeIII fragment from pUC8 had inadvertently been ligated at the junction and introduced a stop codon at the very beginning of spoIIIG. The second mutation, spoIIIG :: cat, was created by insertion of a chloramphenicol cartridge between codons 166 and 167 of spoIIIG so that it could easily be moved to various genetic backgrounds. Both mutations display the same stage III phenotype as the original spoIIIG mutant (Fig. 2).

We anticipated that spoIIIG was not the third gene of the spoIIG operon because no spo operon to date has been described to contain genes in which mutations block sporulation at different stages. A restriction fragment overlapping the distal part of spoIIGB and the proximal part of spoIIIG (see Fig. 1) was used to integrate a plasmid at that location into the chromosome. Both open reading frames were reconstituted, but the spoIIIG gene was moved away from the $s p o I I G$ operon by $\sim 5 \mathrm{~kb}$. A similar plasmid integration into the spoIIA operon leads to a $\mathrm{Spo}^{-}$phenotype by separating the distal spoIIAC gene from its promoter (Piggot et al. 1984). Conversely, clones obtained by integration of a plasmid between the spoIIGB and spoIIIG cistrons were brown on nutrient agar plates and full of bright refractile spores, as judged by phase-contrast microscopy. This result confirms a similar observation by Kenney and Moran (1987) and indicates that the 427-bp DNA fragment used in that experiment contains a promoter for spoIIIG.

The distal part of the spoIIIG gene was cloned by the 


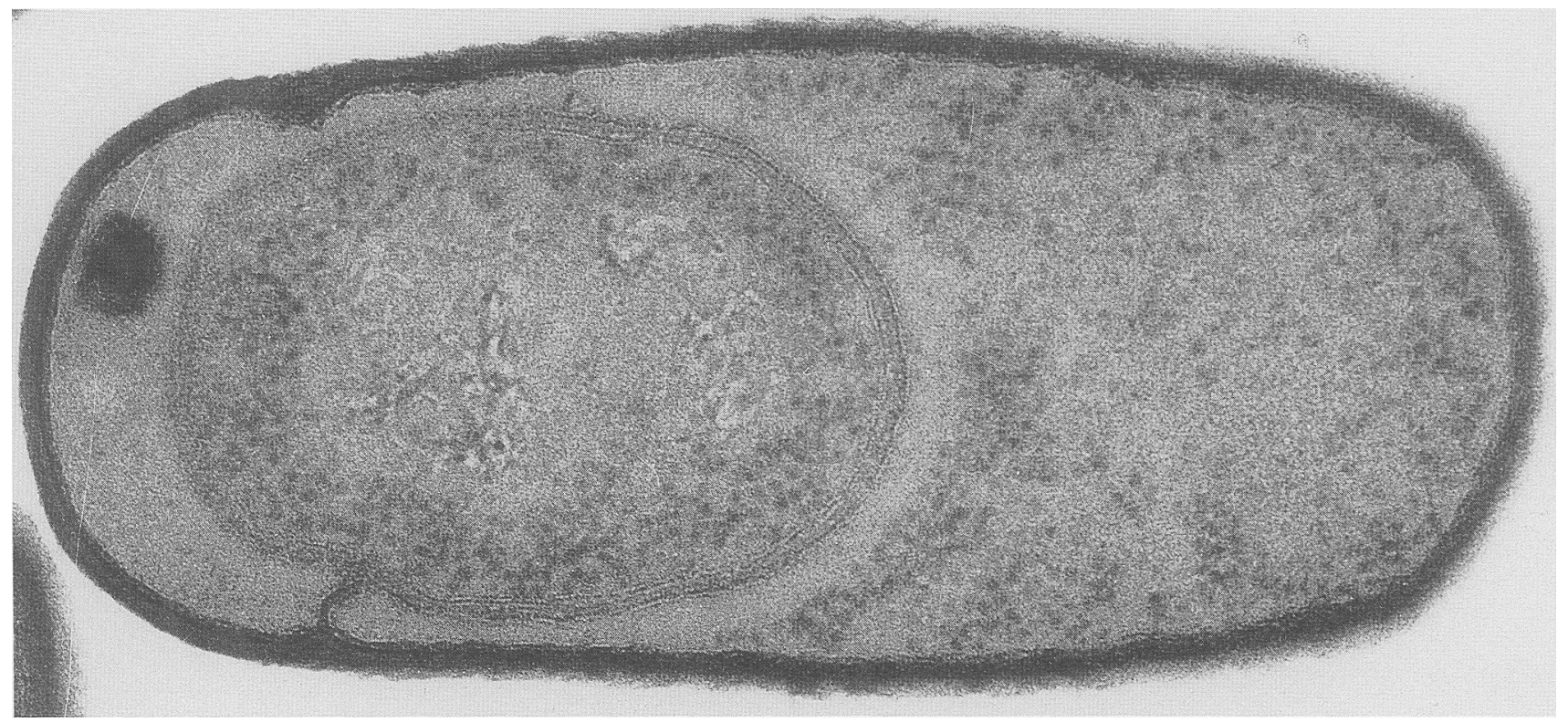

Figure 2. Electron micrograph of a spoIIIG mutant. The MO428 strain was grown in DS medium and cells were harvested $5 \mathrm{hr}$ after the end of exponential growth (kindly provided by A. Ryter).

'walking' technique devised by Youngman et al. (1984). A plasmid that could be selected for and replicated in Escherichia coli was integrated into the $B$. subtilis chromosome at the distal border of our original insert (Fig. 1). Chromosomal DNA of that strain was purified, cut with various restriction enzymes, ligated at low DNA concentration, and introduced by transformation in $E$. coli. Clones were obtained that carried overlapping DNA fragments, the largest one extending $2.9 \mathrm{~kb}$ downstream of our initial insert.

\section{spoIIIG encodes a $\sigma$-like polypeptide}

Nucleotide sequence of the spoIIIG locus (Fig. 3) was assembled from various overlapping restriction fragments and extended our previously published sequence of the spoIIGB locus (Stragier et al. 1984). An open reading frame encoding a 260-residue, 30,055-m.w. polypeptide was found at the location indicated by Kobayashi and Anaguchi (1985). The translational start was assigned to a GTG codon preceded by a good ribosome binding site; it has been confirmed by analysis of the spoIIIG polypeptide, the f-Met residue being posttranslationaly removed (Sun et al. 1989). The stop codon is immediately followed by an inverted repeat that could be a transcription termination signal.

To localize the distal border of the spoIIIG operon, we followed the same strategy as described above. A restriction fragment carrying the last 94 codons of spoIIIG and extending 91-bp downstream (see Fig. 1) was used to integrate a plasmid at that location into the chromosome. The resulting clones displayed a $\mathrm{Spo}^{+}$phenotype, indicating that there is no other spo gene farther downstream, depending on transcription initiated at the spoIIIG promoter.
Close examination of the predicted sequence of the spoIIIG product revealed motifs that were familiar to us (Stragier et al. 1985; Stragier 1986), because they are shared by most bacterial $\sigma$-factors. The sequence of the spoIIIG polypeptide can be aligned on its entire length with the sequences of eight other bacterial $\sigma$-factors (Fig. 4). Three domains of $\sigma$-factors play important functional roles. One is involved in binding to core RNA polymerase and has been predicted to be the most conserved region in bacterial $\sigma$-factors (Stragier et al. 1985; Gribskov and Burgess 1986). Extension of the alignments to nine polypeptides reinforces this proposal (see Fig. 4). The two other domains should contact specific nucleotides in the -10 and -35 regions of promoters and have now been localized (for review, see Helmann and Chamberlin 1988). A common framework is ensured by the presence of some conserved residues interspersed among variable amino acids that mediate recognition specificity. It is striking to observe (Fig. 4) that both in the -10 and the -35 region, the spoIIAC and spoIIIG polypeptides share almost identical sequences, with only one difference in each case (the $\mathrm{F}$ and $\mathrm{Y}$ residues in their -10 regions are functionally equivalent). It can be expected that if these polypeptides are actually $\sigma$-factors, their cognate promoters will be very similar.

\section{Temporal and spatial expression of spoIIIG}

Determination of the upstream border of the spoIIIG operon has indicated the presence of a promoter for spoIIIG in the 427-bp HindIII-PstI fragment that overlaps spoIIGB and spoIIIG (Fig. 1). This fragment was cloned upstream of a promoterless $1 a c Z$ gene and recombined as a single copy into the amy region of the chromosome (see Experimental procedures). $\beta$-Galactosidase was assayed during growth and sporulation (Fig. 5). It 
TAA מAATT'TTATGGTTAGAACCCCTTGATTTTACAGGGÄTTTCCTGATTTCGACAGTT'TTTCGGTCTGÅTGCAGTGCATATTTTTCCCACCCAAGGAG

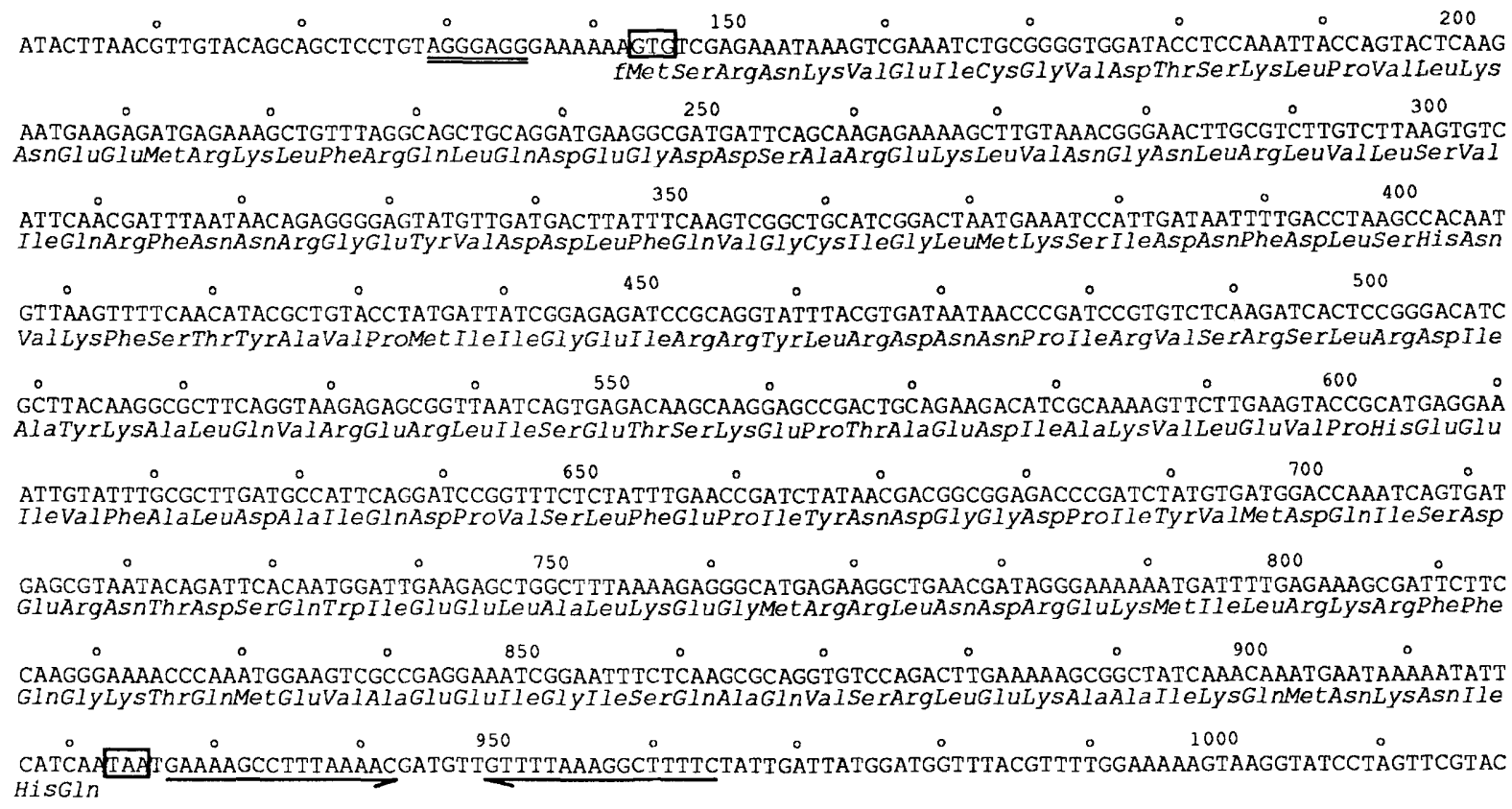

Figure 3. Structure of the spoIIIG gene. The nucleotide sequence was determined on both strands from overlapping restriction fragments cloned in the Bluescript phagemid (Short et al. 1988) and subjected to the dideoxy sequencing procedure of Sanger et al. (1977), with the modifications of Biggin et al. (1983). Only the nontranscribed DNA strand is shown, starting from the spoIIGB stop codon, with the predicted amino acid sequence. Initiation and stop codons are boxed. The ribosome-binding site is underlined. A putative transcription termination signal is shown by arrows.

started to be synthesized $2.5 \mathrm{hr}$ after the end of exponential growth $\left(t_{2.5}\right)$ and was accumulated during the next 2 hr. Such a timing of expression is in good accordance with the developmental stage at which the spoIIIG product is needed. Transcription of spoIIIG is turned on $1 \mathrm{hr}$ later than SpoIID, a gene activated by $\sigma^{\mathrm{E}}$ (Stragier et al. 1988), and $2 \mathrm{hr}$ later than spoIIG itself (Kenney and Moran 1987).

The dependence of spoIIIG expression on the products of other spo genes was analyzed by introducing the spoIIIG-lacZ fusion into various asporogenous strains. Results given in Table 1 indicate that spoIIIG transcription is shut off by all stage II mutations (with two exceptions discussed later), as well as by mutation in spoIIIA, and severely impaired by a spoIIIF mutation. Conversely, spoIIIG expression is almost normal or even enhanced in spoIIIC, spoIIID, and spoIIIE backgrounds. Interestingly spoIIIG transcription is also abolished in a strain mutated in spoIIIG itself. This result will be analyzed later (see Discussion).

With the sole exception of the spoIIIE mutation, such a dependence pattern is typical of genes specifically expressed in the forespore, as spoVA (Errington and Mandelstam 1986b), gdh, and ssp genes (Mason et al. 1988). Fractionation methods have been devised that give a good estimation of the compartmentalization of a gene product during late stages of sporulation (Errington and Mandelstam 1986b). Following a similar approach, $\beta$-galactosidase (under the control of the spoIIIG promoter) was analyzed and compared to glucose dehydrogenase, the product of the gdh gene. After fractionation of a sample of sporulating cells (harvested around $t_{5}$ ), $92 \%$ of glucose dehydrogenase and $\beta$-galactosidase were found in the forespore, their specific activities being 20 -fold higher in forespore than in mother cell. Moreover, essentially all of the $\beta$-galactosidase and glucose dehydrogenase synthesized during sporulation were found to end up in mature spores (data not shown).

\section{Discussion}

spoIIIG, a new member of a multigene family

The spoIIIG gene has been identified by reverse genetics and found to encode a $\sigma$-like polypeptide. A similar situation has been encountered with the spoIIAC gene, which was already defined by standard genetic analysis and, despite the absence of supporting biochemical evidence, proposed to code for a developmental $\sigma$-factor (Errington et al. 1985; Stragier 1986). In the accompanying paper, Sun et al. (1989) demonstrate that both spoIIAC and spoIIIG gene products are actually new $\sigma$-factors, $\sigma^{\mathrm{F}}$ and $\sigma^{\mathrm{G}}$. In accordance with the rules proposed by Losick et al. (1986), the spoIIAC and spoIIIG genes should alternatively be named $\operatorname{sig} F$ and $\operatorname{sig} G$.

The tandem arrangement of spoIIIG with spoIIGB, the gene encoding pro- $\sigma^{\mathrm{E}}$, suggests that these two genes resulted from a duplication of an ancestral gene, as previously proposed for two genes of the spoVA operon (Errington et al. 1985). Seven $B$. subtilis genes encoding $\sigma$ factors have now been cloned. From their location on 

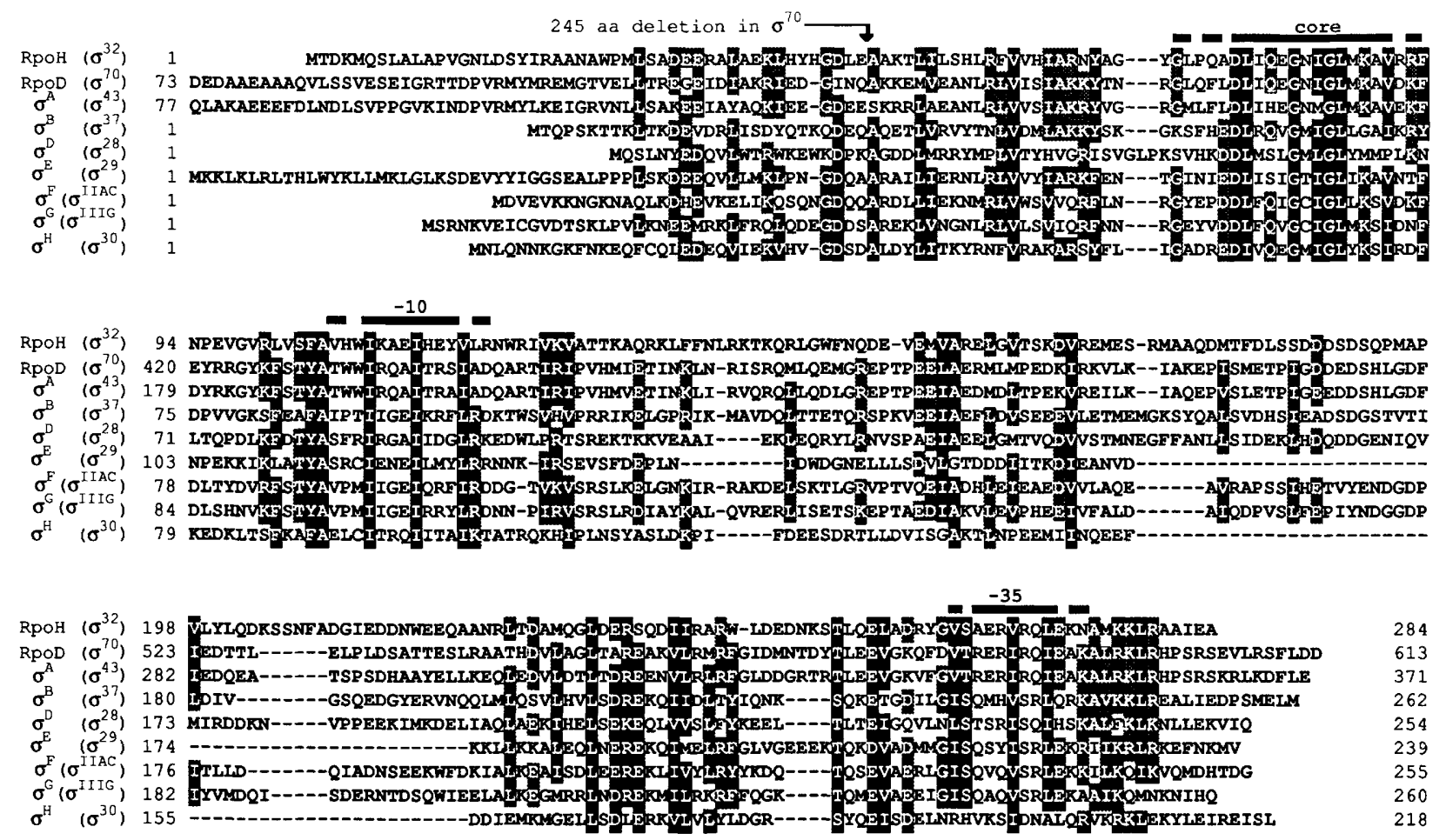

Figure 4. Alignment of amino acid sequences of bacterial $\sigma$-factors. Two $\sigma$-factors from $E$. coli $\left(\sigma^{32}\right.$ and $\left.\sigma^{70}\right)$ are aligned with seven $\sigma$-factors from $B$. subtilis. Their alternate names are given. A 245 -amino-acid deletion corresponding to residues $130-374$ has been introduced in the $\sigma^{70}$ sequence at the position shown by the arrow. The one-letter amino acid notation is used. Chemically similar amino acids are defined as the following groups: $D$ and $E ; K$ and $R ; S$ and $T ; F$ and $Y, I, L$, and V. Gaps have been introduced to maximize the alignments and are shown by hyphens. A black background indicates positions occupied by identical or chemically similar amino acids in eight or nine proteins. Positions at which six or seven residues are identical or similar are indicated by a stippled background. The locations of potential functional domains are indicated. Bacteriophage $\sigma$-factor sequences have not been included because they disrupt many of the most highly conserved blocks (for a thorough discussion and individual references, see Helmann and Chamberlin 1988).

the chromosome (Fig. 6), it can be speculated that this multigene family arose by successive duplications, some of these reflecting duplications of the ancestral chromosome, as suggested by Binnie et al. (1986). The latter hypothesis would be strengthened if additional sig genes were to be found in the $300^{\circ}$ region of the chromosome.

\section{Expression of spoIIIG is compartmentalized}

spoIIIG expression is controlled by its own promoter located in the 323-bp preceding its ribosome-binding site. This promoter is activated at $t_{2.5}$ and is under the dependence of most stage II gene products, as well as products of the spoIIIA, spoIIIF, and spoIIIG genes. The presence of $\beta$-galactosidase in a spoIIF strain carrying a spoIIIGlac $Z$ fusion can be correlated with the oligosporogenous phenotype of that strain, which produces $10-30 \%$ of the wild-type amount of spores. The striking difference observed between the two spoIID alleles was also reported by Mason et al. (1988) in their study of $g d h$ and $s s p$ genes. It indicates that the mutations (each of which completely prevents spore production) must affect the spoIID product in a very different way, the spoIID298 mutation allowing expression of some post-stage II genes.
Altogether these results suggest that forespore-specific gene expression is a consequence of activation of the spoIIIG promoter exclusively in the forespore, which could be controlled by the spoIIIA and spoIIIF products. However, the absolute dependence of spoIIIG transcription on $\sigma^{G}$ itself implies that some other promoter must be involved in spoIIIG expression. Our preliminary results indicate that spoIIIG is expressed at an early time by read through from the spoIIG operon (C. Karmazyn-Campelli and P. Stragier, unpubl.). The synthesis of $\boldsymbol{\sigma}^{\mathrm{G}}$ before septation, when no forespore-specific promoter is expressed, suggests that $\sigma^{G}$ activity might require some special environment that would be achieved only in the forespore (and be dependent on the spoIIIA and spoIIIF products). $\sigma^{\mathrm{G}}$ would then enhance its own synthesis only in the forespore by activation of a promoter located between spoIIGB and spoIIIG. This burst of $\sigma^{G}$ synthesis would, in turn, displace $\sigma^{\mathbf{E}}$ and allow forespore-specific gene expression. Thus, autoregulation of spoIIIG could play a major role in compartmentalization of gene expression.

Genes expressed specifically in the forespore or the mother cell follow opposite patterns for their dependence on stage III gene products (Errington and Mandelstam 1986b; Kunkel et al. 1988; Mason et al. 1988). Ex- 


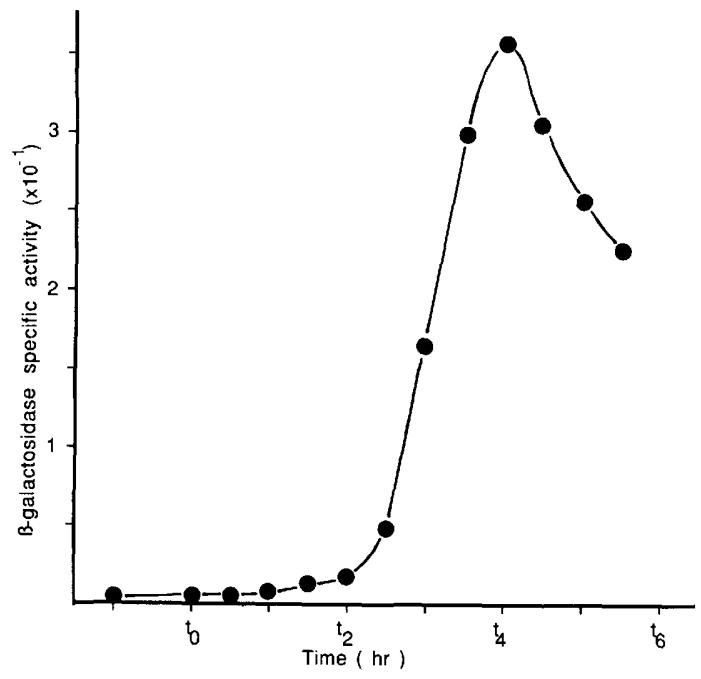

Figure 5. Time course of spoIIIG-lacZ expression. The specific activity of $\beta$-galactosidase was measured during growth and sporulation in DS medium of strain MO464, a JH642 derivative containing a spoIIIG-lacZ fusion inserted by a double recombination event at the amy locus. The background level found in a strain harboring the same lacZ insertion without any promoter was substracted.

pression of spoIIIG shows a forespore-type dependence pattern, and fractionation experiments confirm that spoIIIG is transcribed predominantly, if not only, in the forespore. These data strongly suggest that the spoIIIG product is a $\sigma$-factor for genes expressed specifically in the forespore, a hypothesis confirmed in the accompanying paper by Sun et al. However, because a spoIIIGlacZ fusion is transcribed actively in a spoIIIE mutant

Table 1. Effect of spo mutations on expression of a spoIIIGlacZ fusion

\begin{tabular}{lc}
\hline spo allele $^{\mathbf{a}}$ & $\beta$-Galactosidase activity \\
\hline spoOI87 & 17 \\
spoIIAA69 & 5 \\
spoIIAC1 & 6 \\
spoIIB131 & 8 \\
spoIID66 & 19 \\
spoIID298 & 90 \\
spoIIE48 & 6 \\
spoIIF96 & 57 \\
spoIIGA 17 & 6 \\
spoIIGBS66 & 5 \\
spoIIIA53 & 12 \\
spoIIIC94 & 49 \\
spoIIID83 & 157 \\
spoIIIE36 & 244 \\
spoIIIF590 & 21 \\
spoIIIG 1 & 6 \\
\hline
\end{tabular}

a The spoO/87 mutation blocks sporulation at stage III (Stragier et al. 1988); contradictory results were obtained with the spoIIIB2 mutation, depending on the origin of the strain used. $b$ Activity is expressed as a percentage of the maximum level of $\beta$-galactosidase observed in wild-type cells between $t_{4}$ and $t_{5}$.

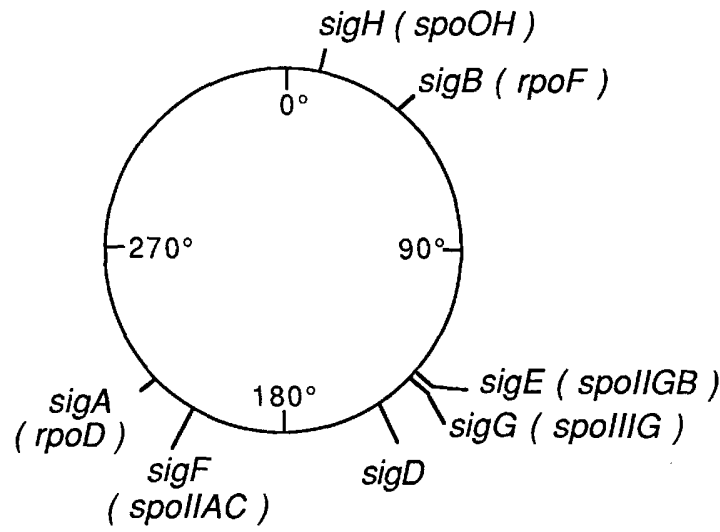

Figure 6. Genetic map of $B$. subtilis sig genes. Locations of genes encoding $\sigma$-factors on the genetic map of $B$. subtilis are indicated with their alternate names. The sigC gene encoding $\sigma^{32}$ has not yet been cloned. The $s i g D$ location was determined by Helmann et al. (1988). Other references are listed in Losick et al. (1986).

while other forespore specific genes are turned off, it follows that the spoIIIE gene product(s) must somehow be required for $\sigma^{\mathrm{G}}$ activity.

\section{Cascades of $\sigma$-factors for switching between developmental stages}

Before any genetic evidence was available, Losick and Pero (1981) proposed that a cascade of $\sigma$-factors governs the sequential expression of gene sets during bacterial sporulation. Four spo genes encoding $\sigma$-factors have now been identified in $B$. subtilis and have been found to control successive steps of development. The spoOH product $\left(\sigma^{\mathbf{H}}\right)$ acts at the very beginning of sporulation, presumably in response to metabolic changes occurring at the end of exponential growth (Carter and Moran 1986; Dubnau et al. 1988). $\sigma^{\mathbf{H}}$ is needed for expression of the spoIIA and spoIIG operons (Errington and Madelstam 1986a; Kenney and Moran 1987). The spoIIAC product $\left(\sigma^{\mathrm{F}}\right)$ is necessary for proper completion of the asymmetric septum (Piggot and Coote 1976) which, in turn, apparently activates processing of pro- $\sigma^{\mathrm{E}}$, the spoIIGB product (Stragier et al. 1988). $\sigma^{\mathrm{E}}$ binds strongly to core RNA polymerase, leading to a major switch of the transcriptional pattern (Haldenwang et al. 1981). $\sigma^{\mathrm{E}}$ is needed for expression of spoIIIG (Table 1), which encodes $\sigma^{\mathrm{G}}$, the $\sigma$-factor activating most, if not all, forespore-specific genes (Sun et al. 1989). Additional $\sigma$ factor(s) may be expected to control mother-cell-specific genes (Kunkel et al. 1988).

Identification of a $\sigma$-factor dedicated to the transcription of genes in the forespore paves the way to elucidation of the control of compartmentalization of gene expression during sporulation. Our results point the pivotal role of the spoIIIA and spoIIIF products in activation of forespore genes. Analyzing their own synthesis and functional role should lead us one step backwards, where the two genomes of the sporulating cell differentiate from each other. 


\section{Experimental procedures}

Strains and media

B. subtilis strains are derivatives of strain $168 \operatorname{trpC2}$ or JH642 trpC2 pheA1. Sporulation mutant strains were provided by S. Cutting, P. Setlow, and J. Errington. The spoIIG mutations have been described (Stragier et al. 1988). The $\Delta 1$ deletion in the spoIIIG locus was created in vitro on cloned DNA fragments and introduced into the $B$. subtilis chromosome by spontaneous exchange with a replicative plasmid carrying the mutated allele, screening for $\mathrm{Spo}^{-}$colonies (Chak et al. 1982). Growth in the absence of antibiotics led to subsequent loss of the plasmid. A cat insertion was introduced into the spoIIIG locus by transformation of $B$. subtilis with a linearized plasmid carrying a $1.5-\mathrm{kb}$ cat fragment from pMIl101 (Donovan et al. 1987) in the BamHI site of the spoIIIG gene. Transformation of $B$. subtilis was made according to Anagnostopoulos and Spizizen (1961). For all sporulation experiments, B. subtilis strains were grown in DS medium (Schaeffer et al. 1965), and chloramphenicol $(5 \mu \mathrm{g} / \mathrm{ml})$ was added if necessary.

Plasmid constructions were performed using the $E$. coli strains DH5 $\alpha$ and JM107. E. coli bacteria were grown in LB medium (Miller 1972) in the presence of the appropriate antibiotics $(50 \mu \mathrm{g} / \mathrm{ml}$ ampicillin, $10 \mu \mathrm{g} / \mathrm{ml}$ tetracycline $)$.

\section{Identification and cloning of the spoIIIG locus}

Fragments of the spoIIG-spoIIIG locus were cloned in the integrative vector pJH101 (Ferrari et al. 1983), usually after a subcloning step in the pUC or Bluescript vectors that introduced convenient restriction sites on the borders of the insert. Homologous recombination by a Campbell insertion inactivated the locus if the fragment did not carry one end of the operon (Piggot et al. 1984).

The rightmost 242-bp DdeI-BamHI fragment from our initial insert (Stragier et al. 1984) was cloned in pUC18 (after filling in the DdeI site), recovered as a SphI-BamHI fragment, and cloned in $\mathrm{p} / \mathrm{H} 101$. The resulting plasmid was introduced into $B$. subtilis and recombined at the spoIIIG locus. Cleaving the chromosomal DNA after this insertion with restriction enzymes and using some of the cloning sites of the original pJH101 vector allowed us to recover the adjacent downstream region of the spoIIIG locus in E. coli, after ligation and transformation (see Youngman et al. 1984).

\section{Construction and analysis of a transcriptional spoIIIG-lacZ fusion}

A 427-bp HindIII-PstI fragment containing the spoIIIG promoter was cloned in pUC8, recovered as a HindIII-BamHI fragment, and cloned in pDG268, a derivative of ptrpBG1 (Shimotsu and Henner 1986), upstream of a promoterless lacZ gene using the translational signals of the $B$. subtilis spoVG gene. After linearization of the plasmid, this fusion was introduced into the $B$. subtilis chromosome of various strains by marker replacement through the adjacent amy regions. All clones selected for chloramphenicol resistance were found to be Amy ${ }^{-}$ on plates. Bacteria harboring this fusion were grown in DS medium. Ten-milliliter samples of culture were harvested at regular intervals, washed with Z buffer (Miller 1972), and kept at $-20^{\circ} \mathrm{C}$. After resuspension in $0.5 \mathrm{ml}$ of $\mathrm{Z}$ buffer, the samples were sonicated and clarified by centrifugation. $\beta$-Galactosidasespecific activity was measured according to Miller (1972) and expressed as nmoles of 2-nitrophenyl- $\beta$-D-galactopyranoside (ONPG) hydrolyzed per minute per milligram of protein.

\section{Fractionation experiments}

$\mathrm{The} \mathrm{Spo}^{+}$B. subtilis strain harboring the integrated spoIIIG$1 a c Z$ fusion was grown and treated as described previously (Mason et al. 1988). Sporulating cells were harvested around $t_{5}$ and separated into mother cell and forespore fractions according to Fujita et al. (1977). Another sample was harvested around $t_{28}$, and the mature spores were treated with lysozyme after detergent sensitization. Extracts were assayed for $\beta$-galactosidase and glucose dehydrogenase, as described by Mason et al. \{1988) and Fujita et al. (1977\}, respectively.

\section{Acknowledgments}

We thank R. Losick for helpful discussion and S. Cutting, P. Setlow, and J. Errington for the gift of strains. We are indebted to A. Ryter for the electron microscopy examinations and to D. Sun and P. Setlow for the fractionation experiments. We are grateful to I. Bouvier and A.M. Guérout-Fleury for artwork and to G. Bogdanoff for typing. This work was supported by a grant from C.N.R.S. (U.R.A. 136) and Fondation pour la Recherche Medicale.

\section{Note added in proof}

While this paper was under review, the sequence of the reading frame located downstream of the spoIIGB gene was reported by E.S. Masuda, H. Anaguchi, K. Yamada, and Y. Kobayashi (Proc. Natl. Acad. Sci. 85: 7637-7641). Their data agree completely with our sequence of the gene identified herein as spoIIIG.

\section{References}

Anagnostopoulos, C. and J. Spizizen. 1961. Requirements for transformation in Bacillus subtilis. J. Bacteriol. 81: 74-76.

Biggin, M.D., T.J. Gibson, and G.F. Hong. 1983. Buffer gradient gels and ${ }^{35} \mathrm{~S}$ label as an aid to rapid DNA sequence determination. Proc. Natl. Acad. Sci. 80: 3963-3965.

Binnie, C., M. Lampe, and R. Losick. 1986. Gene encoding the $\sigma^{37}$ species of RNA polymerase $\sigma$ factor from Bacillus subtilis. Proc. NatI. Acad. Sci. 84: 1784-1788.

Carter, H.L. III and C.P. Moran Jr. 1986. New RNA polymerase $\sigma$ factor under spoO control in Bacillus subtilis. Proc. Natl. Acad. Sci. 83: 9438-9442.

Chak, K.F., H. DeLencastre, H.M. Liu, and P.J. Piggot. 1982. Facile in vivo transfer of mutations between the Bacillus subtilis chromosome and a plasmid harbouring homologous DNA. J. Gen. Microbiol. 128: 2813-2816.

Donovan, W., L. Zheng, K. Sandman, and R. Losick. 1987. Genes encoding spore coat polypeptides from Bacillus subtilis. J. Mol. Biol. 196: 1-10.

Dubnau, E., J. Weir, G. Nair, H.L. Carter III, C.P. Moran Jr., and I. Smith. 1988. Bacillus sporulation gene spoOH codes for $\sigma^{30}\left(\sigma^{\mathrm{H}}\right)$. I. Bacteriol. 170: 1054-1062.

Duncan, I. 1987. The bithorax complex. Annu. Rev. Genet. 21: $285-319$.

Errington, J. and J. Mandelstam. 1986a. Use of $1 a c Z$ gene fusions to determine the dependence pattern of the sporulation operon spoIlA in spo mutants of Bacillus subtilis. I. Gen. Microbiol. 132: 2967-2976.

- 1986b. Use of a lacZ gene fusion to determine the dependence pattern and the spore compartment expression of sporulation operon spoVA in spo mutants of Bacillus subtilis. J. Gen. Microbiol. 132: 2977-2985.

Errington, J., P. Fort, and J. Mandelstam. 1985. Duplicated sporulation genes in bacteria. Implication for simple developmental systems. FEBS Lett. 188: 184-188. 
Ferrari, F.A., A. Nguyen, D. Lang, and J.A. Hoch. 1983. Construction and properties of an integrative plasmid for $\mathrm{Ba}$ cillus subtilis. J. Bacteriol. 154: 1513-1515.

Fujita, Y., R. Ramaley, and E. Freese. 1977. Location and properties of glucose dehydrogenase in sporulating cells and spores of Bacillus subtilis. I. Bacteriol. 132: 282-293.

Gribskov, M. and R. Burgess. 1986. Sigma factors from E. coli, $B$. subtilis, phage SPOl and phage T4 are homologous proteins. Nucleic Acids Res. 14: 6745-6763.

Haldenwang, W.G., N. Lang, and R. Losick. 1981. A sporulation-induced sigma-like regulatory protein from $B$. subtilis. Cell 23: 615-624.

Helmann, J.D. and M.J. Chamberlin. 1988. Structure and function of bacterial sigma factors. Annu. Rev. Biochem. 57: 839-872.

Helmann, J.D., L.M. Marquez, V.L. Singer, and M.J. Chamberlin. 1988. Cloning and characterization of the Bacillus subtilis sigma-28 gene. In Genetics and biotechnology of bacilli (ed. A.T. Ganesan and J.A. Hoch), vol. 2, pp. 189-193. Academic Press, San Diego, California.

Kenney, T.J. and C.P. Moran Jr. 1987. Organization and regulation of an operon that encodes a sporulation-essential sigma factor in Bacillus subtilis. J. Bacteriol. 169: 3329-3339.

Kobayashi, Y. and H. Anaguchi. 1985. Cloning, amplification, and characterization of sporulation genes, especially spoIIG, of Bacillus subtilis. In Molecular biology of microbial differentiation (ed. J.A. Hoch and P. Setlow), pp. 85-94. American Society for Microbiology, Washington, D.C.

Kunkel, B., K. Sandman, S. Panzer, P. Youngman, and R. Losick. 1988. The promoter for a sporulation gene in the spoIVC locus of Bacillus subtilis and its use in studies of temporal and spatial control of gene expression. I. Bacteriol. 170: 3513-3522.

LaBell, T.L., J.E. Trempy, and W.G. Haldenwang. 1987. Sponulation-specific $\sigma$ factor $\sigma^{29}$ of Bacillus subtilis is synthesized from a precursor protein, $\mathrm{p}^{31}$. Proc. Natl. Acad. Sci. 84: $1784-1788$.

Losick, R. and J. Pero. 1981, Cascades of sigma factors. Cell 25: $582-584$.

Losick, R., P. Youngman, and P. Piggot. 1986. Genetics of endospore formation in Bacillus subtilis. Annu. Rev. Genet. 20: $625-669$.

Maniatis, T., E.F. Fritsch, J. Lauer, and R.M. Lawn. 1980. The molecular genetics of human hemoglobins. Annu. Rev. Genet. 14: 145-178.

Mason, J.M., R.H. Hackett, and P. Setlow. 1988. Studies on the regulation of expression of genes coding for small acid-soluble proteins of Bacillus subtilis spores using lacZ gene fusions. J. Bacteriol. 170: 239-244.

Miller, J.H. 1972. Experiments in molecular genetics. Cold Spring Harbor Laboratory, Cold Spring Harbor, New York.

Panzer, S., R. Losick, D. Sun, and P. Setlow. 1989. Evidence for an additional temporal class of gene expression in the forespore compartment of sporulating cells of Bacillus subtilis. J. Bacteriol. 171: 561-564.

Piggot, P.J. and J.G. Coote. 1976. Genetic aspects of bacterial endospore formation. Bacteriol. Rev. 40: 908-962.

Piggot, P.J., C.A.M. Curtis, and H. DeLencastre. 1984. Use of integrational plasmid vectors to demonstrate the polycistronic nature of a transcriptional unit (spoIIA) required for sporulation of Bacillus subtilis. I. Gen. Microbiol. 130: $2123-2136$.

Sanger, F., S. Nicklen, and A.R. Coulson. 1977. DNA sequencing with chain-terminating inhibitors. Proc. Natl. Acad. Sci. 74: 5463-5467.

Schaeffer, P., J. Millet, and J.P. Aubert. 1965. Catabolite repres- sion of bacterial sporulation. Proc. Natl. Acad. Sci. 54: 704711.

Shimotsu, H. and D. Henner. 1986. Construction of a single copy integration vector and its use in analysis of the trp operon of Bacillus subtilis. Gene 43: 85-94.

Short, J.M., J.M. Fernandez, J.A. Sorge, and W.D. Huse. 1988. $\lambda Z A P:$ A bacteriophage expression vector with in vivo excision properties. Nucleic Acids Res. 16: 7583-7600.

Stragier, P. 1986. Comment on 'Duplication genes in bacteria' by J. Errington, P. Fort, and J. Mandelstam. (FEBS Lett. 188: 184-188, 1985). FEBS Lett. 195: 9-11.

Stragier, P., C. Bonamy, and C. Karmazyn-Campelli. 1988. Processing of a sporulation sigma factor in Bacillus subtilis: How morphological structure could control gene expression. Cell 52: 697-704.

Stragier, P., C. Parsot, and J. Bouvier. 1985. Two functional domains conserved in major and alternate bacterial sigma factors. FEBS Lett. 187: 11-15.

Stragier, P., J. Bouvier, C. Bonamy, and J. Szulmajster. 1984. A developmental gene product of Bacillus subtilis homologous to the sigma factor of Escherichia coli. Nature 312: $376-378$.

Sun, D., P. Stragier, and P. Setlow. 1989. Identification of a new $\sigma$-factor involved in compartmentalized gene expression during sporulation of Bacillus subtilis. Genes Dev. 3: 141149.

Trempy, J.E., C. Bonamy, J. Szulmajster, and W.G. Haldenwang. 1985. Bacillus subtilis sigma factor $\sigma^{29}$ is the product of the sporulation-specific gene spoIIG. Proc. Natl. Acad. Sci. 82: 4189-4192.

Youngman, P., J.B. Perkins, and R. Losick. 1984. A novel method for the rapid cloning in Escherichia coli of Bacillus subtilis chromosomal DNA adjacent to Tn917 insertions. Mol. Gen. Genet. 195: 424-433. 


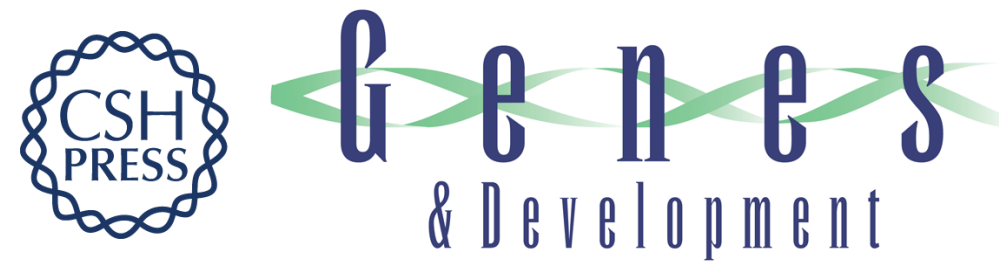

\section{Tandem genes encoding sigma-factors for consecutive steps of development in Bacillus subtilis.}

C Karmazyn-Campelli, C Bonamy, B Savelli, et al.

Genes Dev. 1989, 3:

Access the most recent version at doi:10.1101/gad.3.2.150

References This article cites 37 articles, 15 of which can be accessed free at:

http://genesdev.cshlp.org/content/3/2/150.full.html\#ref-list-1

License

Email Alerting

Service right corner of the article or click here.

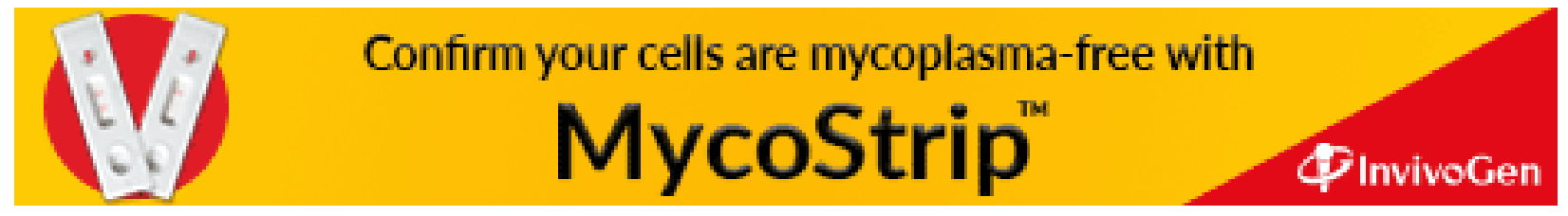

